\title{
Aflatoxin in Raw and Salt-Roasted Nuts (Pistachios, Peanuts and Walnuts) Sold in Markets of Tabriz, Iran
}

\author{
Alireza Ostadrahimi ${ }^{1}$; Fereshteh Ashrafnejad ${ }^{2}$; Abdolhassan Kazemi ${ }^{2, *}$; Nafiseh Sargheini ${ }^{3}$; \\ Reza Mahdavi ${ }^{2}$; Mohammadreza Farshchian ${ }^{4}$; Sepideh Mahluji ${ }^{3}$ \\ ${ }_{1}^{1}$ Nutritional Research Center, Faculty of nutrition, Tabriz University of Medical Sciences, Tabriz, IR Iran \\ ${ }_{3}^{2}$ Liver and Gastrointestinal Diseases Center, Tabriz University of Medical Sciences, Tabriz, IR Iran \\ ${ }^{3}$ Department of Biochemistry and Nutrition, Faculty of Nutrition, Tabriz University of Medical Sciences, Tabriz, IR Iran \\ ${ }^{4}$ Department of Health of Environment, Tabriz University of Medical Sciences, Tabriz, IR Iran \\ ${ }^{*}$ Corresponding author: Abdolhassan Kazemi, Liver and Gastrointestinal Diseases Center, Tabriz University of Medical Sciences, Tabriz, IR Iran. Tel: +98-9149164494, Fax: +98- \\ 4113346951, E-mail: kazemi1338@gmail.com
}

Received: October 20, 2012; Revised: April 29, 2013; Accepted: May 8, 2013

\begin{abstract}
Background: Nuts are one of the main consumed snacks worldwide and also have an important role among Iranian's food habits. Natural contamination of nuts with aflatoxin is unavoidable and causes a special challenge for nuts safety and quality.

Objectives: The purpose of this research was to study the aflatoxin contamination in commercially-available nuts (pistachio, walnut and peanut)in the markets of Tabriz, Iran.

Materials and Methods: Sixty two samples of $50 \mathrm{~g}$ salt-roasted peanuts and pistachios and 109 samples of $50 \mathrm{~g}$ pure pistachios, walnuts and peanuts were collected from different areas of local markets. After the initial preparations, ELISA test was performed for Aflatoxin measurement.

Results: Result showed that walnut (90\%) and pure pistachio (2.3\%) were the most and least contaminated samples, respectively. Mean aflatoxin contamination in the salt-roasted samples $(19.88 \pm 19.41 \mu \mathrm{g} / \mathrm{kg})$ was significantly higher than the pure ones $(6.51 \pm 9.4 \mu \mathrm{g} / \mathrm{kg})(\mathrm{P}<$ 0.001). Respectively, $58.6 \%, 48.4 \%$ and $47.6 \%$ of salt-roasted pistachios, salt-roasted peanuts and walnut samples had aflatoxin contamination, which were more than the maximum tolerated level of Iran (MTL, $15 \mathrm{ppb}$ ).

Conclusions: It was concluded that aflatoxin content of nuts should be monitored regularly to minimize the risk of aflatoxin hazard and ensure the food safety and quality.
\end{abstract}

Keywords: Aflatoxin; Nuts; Enzyme-Linked Immunosorbent Assay

\section{Background}

Fungi produce several metabolites and develop rapidly on different kinds of foods (1). These microorganisms can easily spread by wind, insects and raining, thus, survive in the environment (2). Molds naturally produce a wide range of metabolites, called mycotoxins. Mycotoxins can have toxic effects on humans and animals tissues and organs (3). They are mentioned as the 21st century concern due to their important pathogenic roles. The most toxic form of mycotoxins is called aflatoxin (AF). Studies have shown that AF contaminates some kinds of foods such as nuts, dried fruits, cereals and tea, since these groups are often exposed to the fungal infestations (4-6). According to the food and agriculture organization (FAO), globally, up to $25 \%$ of the foodstuff are contaminated with mycotoxins (7).

Among the nut products, pistachios are extremely contaminated with $\mathrm{AF}(8)$. In an Iranian study, the mean level of $\mathrm{AF}$ in pistachios was recorded as $7.3 \pm 53.2 \mathrm{ng} / \mathrm{g}$ which was lower than the AF maximum tolerated level (MTL) of Iran (8). In another study in Saudi Arabia, the concentration of AF in peanuts was $28 \mu \mathrm{g} / \mathrm{kg}$ (9). The most important risk of AF for human and also animals is due to chronic dietary exposure (10). Various epidemiologic studies have indicated that $\mathrm{AF}$, a serious concern to nuts safety and quality, causes human gastrointestinal disorders, hepatic neoplasm and liver cell carcinoma $(3,11)$. Even small amounts of AF in the foods, threaten the public health (1). However, countries try to control the levels of mycotoxins particularly AF in food and agricultural products; sometimes it is difficult to deal with several factors and lower the AF levels (12). Nuts AF is not influenced by temperature and remains active even in $160^{\circ} \mathrm{C}$ (13). In some countries like Iran, production and consumption of nuts (untreated and salt-roasted) have been increased $(14,15)$. Since nuts are known as healthy foods and also have pleasant tastes, people have a great tendency to consume them instead of other snacks such as chips and popcorns (16). 


\section{Objectives}

Fungal contamination is currently a public health concern and there is a global trend to reduce its regarding problems. Considering the fact that nuts consumption is excessive in Iran (1), the aim of this study was to determine the AF levels of Iranian nuts such as untreated and salt-roasted pistachios and peanuts as well as untreated walnuts.

\section{Materials and Methods}

\subsection{Samples}

One hundred and nine samples of untreated nuts (pistachios, walnuts, and peanuts) and 62 samples of saltroasted nuts (pistachios and peanuts) were collected randomly (50 g of each) (area sampling) from different parts of Tabriz city, delivered in sterile packets, moved to a laboratory and kept in a cool place $\left(3-5^{\circ} \mathrm{C}\right)$ maximum for three days. Nuts were surface-sterilized in $4 \%$ sodium hypochlorite for two minutes, diluted with distilled water three times to a concentration of $2 \%$, rinsed in $100 \mathrm{~mL}$ distilled water and then let to dry.

\subsection{Aflatoxin Analysis}

Samples were analyzed by the ELISA method. EuroClone total AF ELISA test kits (EuroClone S.P.A: Italy, code: EEM002096 format 96 tests) were used for analysis. AF extraction was carried out according to the manufacturer's instructions (EuroClone S.P.A). For this purpose, $10 \mathrm{~g}$ of grinded samples was taken and $50 \mathrm{~mL}$ of $33 \%$ methanol solution (methanol: distilled water, 30:60) added, shaken for two minutes and then let settle for 15 minutes at room temperature. Then, the extract was filtered through a Whatman $\mathrm{N}^{\circ} 1$ filter paper, the clear supernatant was diluted 1:2 with $33 \%$ methanol solution $(1 \mathrm{~mL}+1 \mathrm{~mL})$ and samples were tested through ELISA kits instructions. The topical density was measured at $450 \mathrm{~nm}$ using ELISA well plate reader. Evaluation of the ELISA data as well as the AF concentration were performed using the software program (EuroClone S.P.A: Italy).

\subsection{Statistical Analysis}

SPSS program version 11.5 was used for statistical analysis (SPSS Institute Inc. Chicago, Illinois). Descriptive statistical analysis was reported as Mean \pm SD and percentages. Comparing the mean differences among the untreated nuts was done by analysis of variance (ANOVA). One sample T-test was used to compare the mean of AF in samples with MTL of Iran. Independent T-test was used to compare the AF means between the two groups of nuts. $P$ value $\leq 0.05$ was considered significant.

\section{Results}

The average recovery and standard deviation for AF levels were $102.13 \pm 8.89 \mu \mathrm{g} / \mathrm{kg}$. Mean of total AFs in untreated and salt-roasted samples were $6.51 \pm 9.4 \mu \mathrm{g} / \mathrm{kg}$ and 19.88 $\pm 19.41 \mu \mathrm{g} / \mathrm{kg}$, respectively. Table 1 presents the mean and range of total AF levels in the analyzed samples. Mean differences of the AF levels between salt-roasted and untreated nuts were significant $(\mathrm{P}<0.001)$. Differences of the means between salt-roasted pistachios and peanuts were not significant $(\mathrm{P}=0.42)$, but between pure pistachios and walnuts as well as walnuts and pure peanuts were significant $(\mathrm{P}<0.001)$. Walnuts with $90.69 \%$ as well as roasted and pure with $2.3 \%$ contamination had the most and least AF incidences, respectively. Table 2 shows the percentages of contaminations with AF in the analyzed samples.

Table 1. Mean and Range of the Total AF levels in the Analysed Samples

\begin{tabular}{|c|c|c|c|}
\hline Types of Nuts & $\begin{array}{l}\text { Mean } \pm S D \\
\mu \mathrm{g} / \mathrm{kg}\end{array}$ & $\begin{array}{l}\text { Range, } \\
\mu \mathrm{g} / \mathrm{kg}\end{array}$ & $\begin{array}{l}\text { Number of } \\
\text { Analysed } \\
\text { Samples }\end{array}$ \\
\hline Untreated $^{\mathrm{a}}$ & $6.51 \pm 9.4$ & $0-38.1$ & 109 \\
\hline Walnut & $14.4 \pm 8.4$ & $0-38.1$ & 43 \\
\hline Pistachio & $0.48 \pm 3.1$ & $0-2.08$ & 43 \\
\hline Peanut & $3.03 \pm 8.6$ & $0-31.7$ & 23 \\
\hline Salt-Roasted ${ }^{a}$ & $19.88 \pm 19.41$ & $0-52.3$ & 62 \\
\hline Pistachio & $22.02 \pm 20.2$ & $0-52.3$ & 29 \\
\hline Peanut & $17.99 \pm 18.7$ & $0-51.7$ & 33 \\
\hline
\end{tabular}

Table 2. Percentage of AF Incidence in Analyzed Samples

\begin{tabular}{lll}
\hline Types of Nuts & $\begin{array}{l}\text { Number of } \\
\text { Samples With AF a } \\
\text { Contamination (\%) }\end{array}$ & $\begin{array}{l}\text { Number of } \\
\text { Analyzed } \\
\text { Samples }\end{array}$ \\
\hline Pure pistachio & $1(2.3)$ & 43 \\
\hline Pure peanut & $4(17.3)$ & 23 \\
\hline Pure walnut & $39(90.69)$ & 43 \\
\hline Salt-roasted pistachio & $16(55.17)$ & 29 \\
\hline Salt-roasted peanut & $5(15.15)$ & 33 \\
\hline
\end{tabular}

a Abbreviation: $\mathrm{AF}$, aflatoxin.

Table 3 shows the numbers and percentages of samples containing AF more than 15 ppb (parts per billion). According to this Table, nuts containing AF of more than 15 ppb were considerable in the salt-roasted samples (pistachios: $58.62 \%$, peanuts: $48.4 \%$ ) and pure walnuts (47.6\%). Figure 1 compares the mean of AF levels among nuts with 
MTL of Iran. Accordingly, mean of AF levels in the roasted pistachios was more than MTL $(\mathrm{P}<0.05)$, but in untreated pistachios and peanuts, was significantly less than MTL (P $<0.001)$. In comparison to MTL of Iran, mean of total AF level in the untreated groups $(6.51 \pm 9.4 \mu \mathrm{g} / \mathrm{kg})$ was significantly low $(\mathrm{P}<0.001)$, while in the salt-roasted samples $(19.88 \pm 19.41 \mu \mathrm{g} / \mathrm{kg})$ was high $(\mathrm{P}=0.05)$.

Table 3. Numbers and Percentages of Samples Containing AF > $15 \mathrm{ppb}$

\begin{tabular}{lll}
\hline Nuts & $\begin{array}{l}\text { Number of Ana- } \\
\text { lyzed Samples }\end{array}$ & $\begin{array}{l}\text { AF }^{\text {a }} \text { containing } \\
\text { samples, No. (\%) }\end{array}$ \\
\hline Untreated walnuts & 43 & $20(47.6)$ \\
$\begin{array}{l}\text { Untreated } \\
\text { pistachios }\end{array}$ & 43 & $6(2.3)$ \\
Untreated peanuts & 23 & $1(4.3)$ \\
Roasted pistachios & 29 & $17(58.62)$ \\
Roasted peanuts & 33 & $16(48.4)$ \\
\hline $\begin{array}{l}\text { a Abbreviation: AF, aflatoxin. } \\
\text { b number of samples with AF levels more than } 15 \mathrm{ppb} .\end{array}$
\end{tabular}

mTL $\square$ roasted $n$ untreated

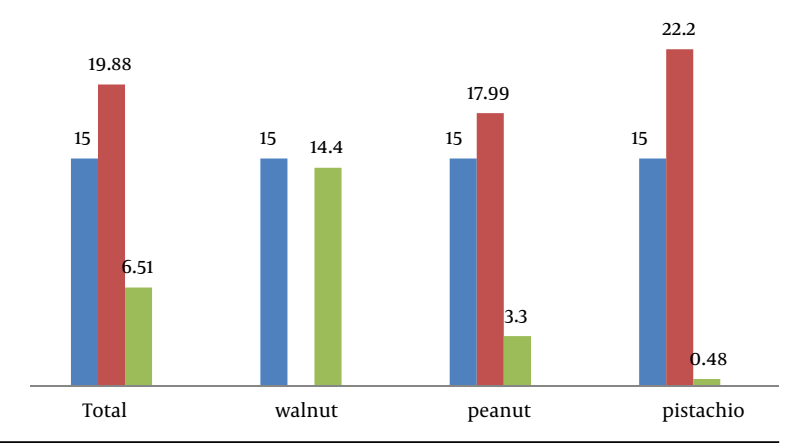

Figure 1. Comparison of Mean AF Levels $(\mu \mathrm{g} / \mathrm{kg})$ of Nuts With MTL of Iran (15 ppb)

\section{Discussion}

Food contamination with $\mathrm{AF}$ is a serious health problem in the community (17). Nuts are subjects of this contamination among the food crops because of their composition and storage conditions $(16,18)$. The obtained results show that the mean of AF levels in the salt roasted group $(19.88 \pm 19.41 \mu \mathrm{g} / \mathrm{kg})$ was more than untreated group (6.51 $\pm 9.4 \mu \mathrm{g} / \mathrm{kg}$ ). In Malaysia, contamination range of nuts and nutty products with AF was 16.6 - $711 \mu \mathrm{g} / \mathrm{kg}$ (19). Research on Korean nuts showed that contamination with AF was in the range of $0.20-28.2 \mu \mathrm{g} / \mathrm{kg}(20)$, which was closer to the present study ( $0-38.1 \mu \mathrm{g} / \mathrm{kg}$ ). In contrast to the findings of Nigerian scientists, our study showed that range of contamination with $\mathrm{AF}$ in roasted peanuts was $0-51.7 \mu \mathrm{g} / \mathrm{kg}$, whereas in their study, it was $10-176 \mathrm{ppb}$ in dry roasted ground nuts. This can be the result of predisposing conditions for the incidence of AF in Nigeria such as unfavorable storage conditions, bad distribution into the nylons, and cross infection by other products of the markets (15).

A study in Zanjan (Iran) indicated that $60 \%$ of salted peanuts and $93.7 \%$ of pure samples were contaminated with AF (21), while findings of the present study showed that $15.15 \%$ of the roasted peanuts and $17.3 \%$ of pure samples were contaminated with AF. This can be the result of susceptible conditions such as high temperature, relatively high humidity, low light intensity, and long-term storage (22). Kladpan et al. (23) in Thailand stated that 3.6\% of raw groundnuts and $50 \%$ of roasted groundnuts had $\mathrm{AF}$ contaminations of more than $20 \mathrm{ppb}$ (MTL of AF levels set by the Thailand ministry of public health), their findings were closer to our study.

In Chun et al. (20) study, $10.6 \%$ of peanut samples contained AF, many of which were roasted. In the present study, the mean of AF contamination levels in walnuts was $14.4 \pm 8.4 \mu \mathrm{g} / \mathrm{kg}$, while in Qatar, walnut samples were free from $\mathrm{AF}$ (24). Juan in morocco reported that incidence of AF in walnuts was 30\% (25), whereas in our study walnut contamination was $90.69 \%$. According to the findings of researchers in Pakistan, shell-less walnuts had the maximum contamination level among all nut samples (11). It seems that high contamination of walnuts in the present study might be due to the fact that all collected samples were shell-less and some of them were damaged. Studies have shown that aflatoxin contamination in damaged and shell-less nuts is more than in-shell nuts $(11,26)$. Cheraghali et al. (8) reported that the total AF level was detected in $28.3 \%$ of pistachios with mean of $7.3 \pm 53.2 \mu \mathrm{g} /$ $\mathrm{kg}$ which was lower than MTL of Iran (15 ppb), while in the present study, incidence of AF was $2.3 \%$ in the pure pistachios and $55.17 \%$ in the salt-roasted ones and mean of $\mathrm{AF}$ levels was $0.48 \pm 3.1 \mu \mathrm{g} / \mathrm{kg}$ in the pure and 22.02 $\pm 20.2 \mu \mathrm{g} /$ $\mathrm{kg}$ in the salt-roasted pistachio samples. Result of an Algerian study showed that $64.5 \%$ of the analyzed pistachio samples were contaminated with AF at levels of 0.4 and $0.7 \mu \mathrm{g} / \mathrm{kg}$ (27). Higher levels of AF in the roasted samples of the present study might be due to the prolonged storage (28), moisture $(29,30)$, and suitable temperature for growth of mycotoxigenic molds (29). In addition, during the sample roasting procedure, fungi are probably destroyed, but their toxins (AF) are stable to dry heat, sometimes even up to $250^{\circ} \mathrm{C}$. Hence, according to the findings of various studies, in Iran, long term storage of roasted nuts in bad conditions can cause AF contaminations in markets and stores.

Although HPLC is the best technique for AF measurement, in the present study, number of samples was high, and unfortunately our funding source was limited, thus ELISA was efficient. On the other hand, there were studies in which results of ELISA techniques were similar to HPLC (31, 32). Besides, ELISA is rapid, cost-effective, accurate, sensitive, easy to use, and convenient (32). High levels of $\mathrm{AF}$ in the food crops especially in nuts are probably due 
to the old and poor methods of manufacturing, storage, transition and marketing. It seems that long-term consumption of the AF-contaminated nuts has carcinogenic and toxigenic effects on the human health. Hence, in Iran, necessary steps should be taken by the health organization and other related agencies to minimize the $\mathrm{AF}$ contamination and also educate people about the danger of $\mathrm{AF}$ in nuts, which are favorable products and used as nourishing and safe snacks in the Iranian society.

\section{Acknowledgements}

The authors would like to thank the Research Council of Nutrition and Liver as well as Gastrointestinal Diseases Center for their scientific assistance.

\section{Authors' Contribution}

Abdolhasan Kazemi and Alireza Ostadrahimi developed the original idea and the protocol. Fereshteh Ashrafnejad, Mohammadreza Farshchian and Abdolhasan Kazemi analyzed and interpreted the data. Abdolhasan Kazemi, Alireza Ostadrahimi, Fereshteh Ashrafnejad and Nafiseh Sargheini abstracted and wrote the manuscript. Reza Mahdavi and Sepideh Mahluji contributed to the development of the protocol, abstracted the data, and prepared the manuscript.

\section{Role of Sponsor}

Liver and Gastrointestinal Diseases Center of Tabriz Medical Sciences University: supported financially and Nutritional Research Center of Tabriz University of Medical Sciences: supported financially as well as provided the lab facilities.

\section{Financial Disclosure}

There is no financial interest to disclosure for this survey.

\section{Funding/Support}

This work was supported by the Research Council of Nutrition and Liver and Gastrointestinal Diseases Center of Tabriz University of Medical Sciences.

\section{References}

1. Khosravi AR, Shokri H, Ziglari T. Evaluation of Fungal Flora in Some Important Nut Products (Pistachio, Peanut, Hazelnut and Almond) in Tehran, Iran. PakJ Nutr. 2007;6(5):460-462.

2. Horn BW. Colonization of wounded peanut seeds by soil fungi: selectivity for species from Aspergillus section Flavi. Mycologia. 2005;97(1):202-17.

3. Kazemi A. Carcinogenic mycotoxins. The 1st Student's Congress of Cancer; Shahed University, Tehran, Iran: April 24-25, 2003. p. 90.

4. Soubra L, Sarkis D, Hilan C, Verger P. Occurrence of total aflatoxins, ochratoxin A and deoxynivalenol in foodstuffs available on the Lebanese market and their impact on dietary exposure of children and teenagers in Beirut. Food Addit Contam Part A Chem Anal Control Expo Risk Assess. 2009;26(2):189-200.

5. Wang J, Liu XM. Contamination of aflatoxins in different kinds of foods in China. Biomed Environ Sci. 2007;20(6):483-7.

6. Rezaeian F, Zamene Milani F, Kazemi A, Mohtadi Nia J, Ghaem Maghami SJ, Jabbari M. Contamination of tea and traditional vegetable distilled to mycotoxin producer fungi. 9 th Iranian $\mathrm{Nu}$ trition Congress.; Tabriz, Iran.: 4-7 September 2006. p. 247.

7. Kabak B. Prevention and Management of Mycotoxins in Food and Feed.Mycotoxins in Food, Feed and Bioweapons. 2010;part 2:201-27.

8. Cheraghali AM, Yazdanpanah H, Doraki N, Abouhossain G, Hassibi M, Ali-abadi S, et al. Incidence of aflatoxins in Iran pistachio nuts. Food Chem Toxicol. 2007;45(5):812-6.

9. Alwakeel SS, Nasse LA. Microbial Contamination and Mycotoxins from Nuts in Riyadh, Saudi Arabia. Am J Food Technol. 2011;6(8):613-30.

10. Gurses M. Mycoflora and Aflatoxin Content of Hazelnuts, Walnuts, Peanuts, Almonds and Roasted Chickpeas (LEBLEBI) Sold in Turkey. Int J Food Prop. 2006;9(3):395-9.

11. Luttfullah G, Hussain A. Studies on contamination level of aflatoxins in some dried fruits and nuts of Pakistan. Food Control. 2011;22(3-4):426-429.

12. Dorner JW. Management and prevention of mycotoxins in peanuts. Food Addit Contam Part A Chem Anal Control Expo Risk Assess. 2008;25(2):203-8.

13. Yazdanpanah H, Mohammadi T, Abouhossain G, Cheraghali AM Effect of roasting on degradation of Aflatoxins in contaminated pistachio nuts. Food Chem Toxicol. 2005;43(7):1135-9.

14. Kashaninejad M, Mortazavi A, Safekordi A, Tabil LG. Some physical properties of Pistachio (Pistaciavera L.) nut and its kernel. J Food Engine. 2006;72(1):30-8.

15. Bankole SA, Ogunsanwo BM, Eseigbe DA. Aflatoxins in Nigerian dry-roasted groundnuts. Food Chem. 2005;89(4):503-506.

16. Sabate J, Ang Y. Nuts and health outcomes: new epidemiologic evidence. Am J Clin Nutr. 2009;89(5):1643S-1648S.

17. Kazemi A, Mohtadi Nia J, Vahed Jabbari M, Ghayour E. Survey of Food Stuff to Carcinogenic Mycotoxins. The 3rd Congress of Medical Plants.; Shahed University, Tehran, Iran:24-25 Oct. 2007.p.386.

18. Molyneux RJ, Mahoney N, Kim JH, Campbell BC. Mycotoxins in edible tree nuts. Int J Food Microbiol. 2007;119(1-2):72-8.

19. Leong Y, Ismail N, Latif AA, Ahmad R. Aflatoxin occurrence in nuts and commercial nutty products in Malaysia. Food Control. 2010;21(3):334-338.

20. Chun HS, Kim HJ, Ok HE, Hwang JB, Chung DH. Determination of aflatoxin levels in nuts and their products consumed in South Korea. Food Chem. 2007;102(1):385-391.

21. Rostami R, Naddafi K, Aghamohamadi A, Saleh HN, Davil MF. Survey of peanut fungal contamination and its relationship with ambient conditions in the Bazar of Zanjan. Iran J Env Health Sci Eng. 2009;6(4):295-300.

22. Pitt JI, Dyer SK, McCammon S. Systemic invasion of developing peanut plants by Aspergillus flavus. Lett Appl Microbiol. 1991;13(1):16-20.

23. Kladpan S, Mahakachanakul W, Yongmanitchai V, Boonyaratanakornkit M, Chinbuti A editors. . Situation of aflatoxin contamination in groundnut and groundnut products in Thailand in 2004. Proceedings of 43rd Kasetsart University Annual Conference.; 1-4 February, 2005, Subject: Animals 2005; Thailand. p. 557-64.

24. Abdulkadar AHW, Al-Ali A, Al-Jedah J. Aflatoxin contamination in edible nuts imported in Qatar. Food Control. 2000;11(2):157-160.

25. Juan C, Zinedine A, Moltó JC, Idrissi L, Mañes J. Aflatoxins levels in dried fruits and nuts from Rabat-Salé area, Morocco. Food Control. 2008;19(9):849-853.

26. Bayman P, Baker JL, Mahoney NE. Aspergillus on tree nuts: incidence and associations. Mycopathologia. 2002;155(3):161-9.

27. Fernane F, Sanchis V, Marin S, Ramos AJ. First report on mould and mycotoxin contamination of pistachios sampled in Algeria. Mycopathologia. 2010;170(6):423-9.

28. AmjadIqbal S, Khalil IA, Shah H. Aflatoxin contents of stored 
and artificially inoculated cereals and nuts. Food Chem. 2006;98(4):699-703.

29. Shakerardekani A, Karim R. Effect of different types of plastic packaging films on the moisture and aflatoxin contents of pistachio nuts during storage. J Food Sci Technol. 2012;50(2):409-411.

30. Youssef MS, El-Maghraby OMO, Ibrahim YM. Mycobiota and Mycotoxins of Egyptian Peanut (Arachis hypogeae L.) Seeds. Int J Bot. 2008;4(4):349-360.
31. Siahi MR, Ansarin M, Tahavori A, Ghaderi F, Nemati M. Determination of aflatoxins in nuts of Tabriz confectionaries by ELISA and HPLC methods. Adv Pharm Bull. 2012;2(1):123-126.

32. Zheng Z, Humphrey CW, King RS, Richard JL. Validation of an ELISA test kit for the detection of total aflatoxins in grain and grain products by comparison with HPLC. Mycopathologia. 2005;159(2):255-63. 